\title{
Diagnostic Accuracy of Transvaginal Ultrasound Versus Hysteroscopy in Evaluation of Endometrial Pathology in Breast Cancer Women Receiving Tamoxifen: Correlation with Histopathological Examination
}

\author{
Doaa Mahmoud Effat, ${ }^{1}$ MD, Manal Khaled Farag, ${ }^{2}$ MD, Kamal Abdelrhaman M Abosonna, ${ }^{3}$ MD.
}

\section{* Corresponding Author: \\ Doaa Mahmoud Effat \\ doaaeffat4560@yahoo.com}

Received for publication May 4, 2021; Accepted June 24, 2021;

Published online June 24, 2021, 2021.

\section{Copyright The Authors published by Al-Azhar} University, Faculty of Medicine, Cairo, Egypt. Users have the right to read, download, copy, distribute, print, search, or link to the full texts of articles under the following conditions: Creative Commons AttributionShare Alike 4.0 International Public License (CC BY-SA 4.0).

doi: 10.21608/aimj.2021.73579.1462.

${ }^{1 .}$ Obstetrics and Gynecology Department, Faculty of Medicine (Girls), Al-Azhar University, Cairo, Egypt.

${ }^{2}$ Radiology Department, Faculty of Medicine (Girls), Al-Azhar University, Cairo, Egypt.

${ }^{3 .}$ General Surgery Department, Faculty of Medicine (Girls), AlAzhar University, Cairo, Egypt.

\begin{abstract}
Background: Multiple endometrial lesions have been reported in tamoxifen -treated breast cancer patients. As a consequence, a thorough uterine cavity examination is often necssary.

Aim of the study: To compare the efficacy of transvaginal ultrasound versus hysteroscopy in detecting the endometrial changes in tamoxifentreated breast cancer patients, and to correlate the findings of both methods with histopathological examination of endometrial biopsies.

Patients and Methods: Twenty seven patients who had mastactomies for breast cancer and receiving tamoxifen (TAM) were enrolled in this prospective study. They subjected to transvaginal ultrasonography (TVUS) and hysteroscopy for endometrial assessment. Endometrial biopsy was taken from all participants for hitstopathological examination. The ultrasongraphic and hysteroscopic findings were compared and correlated with the histopathological results.

Results: The diagnostic accuracy of TVUS versus hysteroscopy in detecting endometrial changes in breast cancer TAM treated women was as follows;TVUS had a sensitivity $(82.4 \%)$, specificity (30.0\%), PPV (66.7\%), NPV (50.0\%) and accuracy (63\%); while, the hysteroscope had sensitivity (94.1\%), specificity (60.0\%), PPV (80.0\%), NPV (85.7\%) and accuracy (81.5\%).

Conclusion: Because of certain discrepancies between TVUS and histopathological results in TAM treated women, TVUS is not the best tool for evaluating the endometrium in those patients. The utility of the hysteroscopic image processing helps in the triage of women who require endometrial surveillance, so it will reduce the pathologist's workload and the patient's apprehension while waiting for histopathology result. Nevertheless hysteroscope cannot establish a conclusive diagnosis of premalignant or malignant lesions, but it provides a direct view for targeted biopsies to create a definitive diagnosis.
\end{abstract}

Keywords: Transvaginal ultrasound; Hysteroscopy; Endometrial Changes; Breast cancer; Tamoxifen.

Disclosure: The authors have no financial interest to declare in relation to the content of this article. The Article Processing Charge was paid for by the authors.

Authorship: All authors have a substantial contribution to the article. 
TVUS is the most widely used gynaecological surveillance method, endometrial thickness is an important surveillance indicator ${ }^{6,7}$.

Hysteroscopy allows for direct visualisation of the endometrium and accurate biopsy tissue sampling, hysteroscopy when used in conjunction with TVUS, enables the detection of intracavitary lesions, as well as determining if a lesion is endometrial or subendometrial ${ }^{1}$.

This study aimed to compare the efficacy of transvaginal ultrasound versus hysteroscopy in detecting endometrial changes in tamoxifen-treated breast cancer patients, and to correlate the findings of both methods with histopathological results of endometrial biopsies.

\section{PATIENTS AND METHODS}

From March 2018-April 2021, a prospective study was performed at Alzharaa University Hospital on 27 women, aged ranging from 32 to 65 , they had undergone to mastectomy for breast cancer and were receiving tamoxifen as an adjuvant therapy. They selected from obstetrics and gynaecology outpatient clinics, as well as surgery and radiology departments. The research was done in light of the 2013 Helsinki Declaration on Human Experimentation and approved by the faculty of medicine's ethical committee for girls (Cairo), Al Azhaer University, Egypt. Before enrolling in this study, all participants gave their written consent to have their endometrium tested using TVUS and hysyeroscopy with D\&C biopsy. Women with masatactomy who were pre- or postmenopausal, symptomatic (vaginal bleeding) or asymptomatic (non vginal bleeding) and receiving TAM as part of their care plan were included. While patients with breast cancer who were not receiving TAM, as well as virgins, were excluded. The patients were subjected to complete history and examination to fulfill inclusion and exclusion criteria. Regarding the history we focused on, date of mastactomy,type of surgery (modified radical mastactomy or lumbectomy), report of breast histopathology, family history of malignancy, adjuvant treatment of breast cancer (chemotherapy, radiotherapy, hormonal treatment), duration of TAM therapy, abnormal vaginal bleeding (menorrhagia, metrorrhagia, postmenopausal bleeding), history of endometrial biopsy \& its result.

All participants were referred to radiology department for radiological assessment for a uterus and adnexea. Real-time ultrasound was performed using Toshiba Aplio 400 (Toshiba Medical Systems, Japan) and GE Logiq P5 (GE Healthcare, , Milwaukee, WI) ultrasound machines with the vaginal transducer $(5-10 \mathrm{MHz})$. Transvaginal probe was used, for measuring the uterus, in longitudinal and transverse views. We checked the myometrium for echo pattern $\&$ its regularity and for any focal lesion.
The endometrium should be measured in a sagittal plane. Endometrial thickness (E T) was measured from the echogenic interface of the anterior basal layer to the echogenic interface of the posterior basal layer, thus representing a double layer. Also it was measured in follicular phase in perimenopausal women because it may reaches to a $16 \mathrm{~mm}$ in secretory phase in normal women ${ }^{8}$ so it may denote missinterpertation.

We considered as per the majority of researchers $\mathbf{8 , 9 , 1 0}$ the average or the cut off value of ET was 5-7 $\mathrm{mm} \& 8 \mathrm{~mm}$ (in follicular phase) in asymptomatic post -and premanopausal women respectively and $<$ $5 \mathrm{~mm} \&<8 \quad \mathrm{~mm}$ in symptomatic post-and premenopausal women respectively .Malignancy is suspected if there was:, an ill defined endometrial/myometrial junction with loss of subendometrial halo, or hetrogenus endometrial echotexture. Ovaries were evaluated for; antral folicles and ovarian volume (especially in cases of young age); ovarian cyst and mass. Douglas pouches evaluated for the presence of abnormalities.

Each participant was then scheduled for a hysteroscopic examination and D\&C biopsy. Hysteroscopy was performed at any time in postmenopausal women. But the Premenopausal women subjected to hysteroscopy during the follicular phase of thier cycle, because the secretory endometrium may be overdiagnosed with endometrial polyps due to the endometrium may appear polypoid during this time ${ }^{\mathbf{1 1}}$. The participant underwent to regional or general anesthesia regarding to anesthesiologists oponion. Hysteroscopy was performed with a diagnostic MGB $4 \mathrm{~mm}$ rigid hysteroscope having a 30-degree oblique aperture view with a $5 \mathrm{~mm}$ sheath. The entire uterine cavity was observed in an orderly manner up to the cornu.Ultimately we commented on the cervix, uterus, endometrium (coloure, thickness, and any focal lesion or polyp). Samples were taken from all aspects of endometrial cavity and fixed in $10 \%$ formalin and sent for histopathological examination in histopathology department of Alzharaa University Hospital. The results of TVUS and hysteroscopy were compared and correlated with the gold standard histopathological reference and statistical analysis was performed.

\section{Statistical analysis}

Astatistical package for social sciences, version 23.0 was used to analyse the results. Qualitative data were expressed as frequency and percentage.Quantitative data were expressed as mean \pm standard deviation (SD) data. The sensitivity, specificity, PPV and NPV were calculated for 2D gray scale ultrasound and hysteroscopic evaluation. $\mathrm{P}$-value $<0.05$ was considered as statistically significant. 


\section{RESULTS}

The demographic data was summarized in (Table 1). The prevalence of normal and abnormal endometrium in the sample population, as determined by TVUS, hysteroscopy, and histopathological examination, was demonstrated in (Table2).

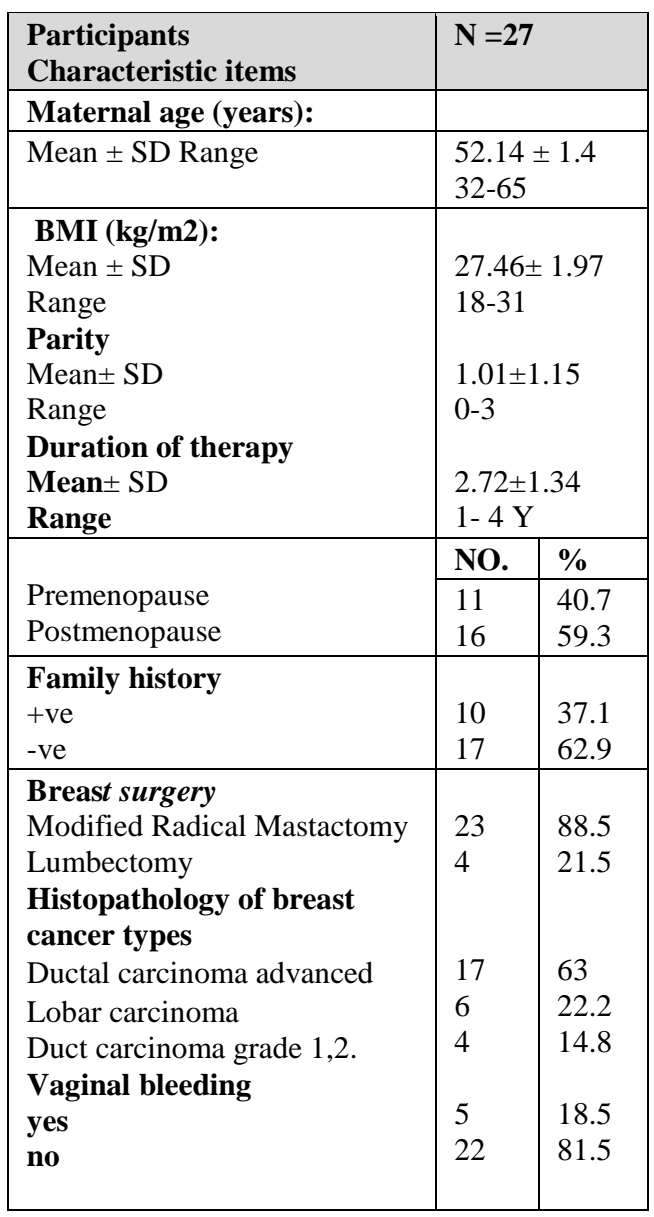

Table 1: Demographic data of the study group.

There was a statiatical insignificant difference between symptomatic and asymptomatic women, regarding, the frequency of endometrial changes which identified by TVUS and hysteroscopy and verified by histopathological results (Table 3). No cases of insufficient tissue sample was reported. When TVUS results were compared to the final histopathology results, $(82.3 \%)$ were true positives, (70\%) were false positives, $(17.7 \%)$ were false negatives, and (30\%) were true negatives (Table4, Figure.1,2,3). However when the hysteroscopic results were compared to the final histopathological result, $(94.1 \%)$ were true positives, while, $(5.9 \%)$ were false negative, $(60 \%)$ were true negatives and $40 \%$ were false positive (Table 4, Figure.4).

The diagnostic efficacy of TVUS and hysteroscopy in the evaluation of endometrial changes in relation to histopathology findings was revealed that;TVUS had sensitivity $(82.4 \%)$, specificity (30.0\%), PPV $(66.7 \%)$, NPV $(50.0 \%)$ and accuracy $(63 \%)$, while ,the hysteroscope had sensitivity $(94.1 \%)$, specificity
(60.0\%), PPV (80.0\%), NPV (85.7\%) and accuracy (81.5\%), (Table 4).

There was no significant difference in the frequency of endometrial changes based on the length of TAM usage, i.e., between patients who had used TAM for< 2 or $>2$ years, $p>0.05$ (Table 5 ).

\begin{tabular}{|c|c|c|}
\hline & \multicolumn{2}{|l|}{ No $=27$} \\
\hline \multicolumn{3}{|l|}{ US findings } \\
\hline \multirow{2}{*}{$\begin{array}{l}\text { Endometrial } \\
\text { thickness measures }\end{array}$} & Mean \pm SD & $9.52 \pm 4.32$ \\
\hline & Range & $3-30 \%$ \\
\hline $\begin{array}{l}\text { Regularity } \\
\text { endometrium } \\
\text { Regular } \\
\text { Irregular }\end{array}$ & $\begin{array}{l}\text { no } \\
15 \\
12 \\
\end{array}$ & $\begin{array}{l}\% \\
55.5 \\
44.5 \\
\end{array}$ \\
\hline \multicolumn{3}{|l|}{$\begin{array}{l}\text { Endometrial } \\
\text { thickness }\end{array}$} \\
\hline Average thickness & 6 & 22.2 \\
\hline $\begin{array}{l}- \text { Increase endometrial } \\
\text { thickness } \\
\text { cystic change }\end{array}$ & 11 & 40.7 \\
\hline $\begin{array}{l}\text {-Increase endometrial } \\
\text { thickness with cystic } \\
\text { change }\end{array}$ & 7 & 25.9 \\
\hline -Polyp & 1 & 3.7 \\
\hline $\begin{array}{l}\text {-Endometrial atrophy } \\
\text { suspicious lesion }\end{array}$ & $\begin{array}{l}2 \\
0\end{array}$ & $\begin{array}{c}7.4 \\
0 \%\end{array}$ \\
\hline $\begin{array}{ll}\text { Associated } & \text { lesions } \\
\text { Adenomyosis } & \end{array}$ & 2 & 7.4 \\
\hline \multicolumn{3}{|l|}{ hysteroscopic findings } \\
\hline -Normal findings & 7 & 25.9 \\
\hline $\begin{array}{l}\text {-Endometrial } \\
\text { hyperplasia }\end{array}$ & 15 & 55.6 \\
\hline -Polyp & 3 & 11.1 \\
\hline -Endometrial atrophy & 2 & 7.4 \\
\hline -Suspicious lesion & 0 & $0 \%$ \\
\hline \multicolumn{3}{|c|}{ Histopathological Examination } \\
\hline Normal findings & 10 & 37.9 \\
\hline $\begin{array}{lr}\text { Abnormal } & \text { findings- } \\
\text { Typical } & \text { simple } \\
\text { endometrial } & \\
\text { hyperplasia } & \\
\end{array}$ & $3^{17}$ & $\begin{array}{l}62.1 \\
11.1\end{array}$ \\
\hline $\begin{array}{l}\text {-TypicalComplex } \\
\text { hyperplasia }\end{array}$ & 5 & 15.8 \\
\hline -Atypical hyperplasia & 4 & 14.8 \\
\hline -Polyp & 3 & 11.1 \\
\hline -Atrophy & 2 & 7.4 \\
\hline -Endometrial cancer & 0 & $0 \%$ \\
\hline
\end{tabular}

Table 2: TVUS, hysteroscopy and histopathlogical findings in study group (Descriptive data). 


\begin{tabular}{|c|c|c|c|c|c|}
\hline \multirow[t]{2}{*}{ Parameters } & \multicolumn{2}{|c|}{ Symptomatic $(n=5)$} & \multicolumn{2}{|c|}{$\begin{array}{l}\text { Asymptomatic } \\
(n=22)\end{array}$} & \multirow[t]{2}{*}{$\begin{array}{l}\mathrm{p} \text { - } \\
\text { value }\end{array}$} \\
\hline & No. & $\%$ & No. & $\%$ & \\
\hline \multicolumn{6}{|l|}{ US findings } \\
\hline Irregular endometrium & 2 & $40.0 \%$ & 10 & $45.5 \%$ & \multirow[t]{2}{*}{0.641} \\
\hline Regular endometrium & 3 & $60.0 \%$ & 12 & $54.5 \%$ & \\
\hline Average thickness & 0 & $0.0 \%$ & 6 & $27.3 \%$ & \multirow[t]{5}{*}{0.153} \\
\hline Diffuse thick endometrium without cystic changes & 2 & $40.0 \%$ & 9 & $40.9 \%$ & \\
\hline Diffuse thick endometrium with cystic changes & 2 & $40.0 \%$ & 5 & $22.7 \%$ & \\
\hline Polyp & 1 & $20.0 \%$ & 0 & $0.0 \%$ & \\
\hline Endometrial atrophy & 0 & $0.0 \%$ & 2 & $9.1 \%$ & \\
\hline \multicolumn{6}{|l|}{ hysteroscopic Finding } \\
\hline Normal finding & 0 & $0.0 \%$ & 7 & $31.8 \%$ & \multirow[t]{5}{*}{0.370} \\
\hline Endometrial hyperplasis & 4 & $80.0 \%$ & 11 & $50.0 \%$ & \\
\hline Polyp & 1 & $20.0 \%$ & 2 & $9.1 \%$ & \\
\hline Endometrial atrophy & 0 & $0.0 \%$ & 2 & $9.1 \%$ & \\
\hline Suspicious lesion & 0 & $0.0 \%$ & 0 & $0.0 \%$ & \\
\hline \multicolumn{6}{|l|}{ histopathological Findings } \\
\hline Normal findings & 0 & $0.0 \%$ & 10 & $45.4 \%$ & \multirow[t]{7}{*}{0.284} \\
\hline Typical simple hyperplasia & 1 & $20.0 \%$ & 2 & $9.1 \%$ & \\
\hline Typical complex hyperplasia & 1 & $20.0 \%$ & 4 & $18.2 \%$ & \\
\hline Atypical hyperplasia & 2 & $40.0 \%$ & 2 & $9.1 \%$ & \\
\hline Polyp & 1 & $20.0 \%$ & 2 & $9.1 \%$ & \\
\hline Atrophy & 0 & $0.0 \%$ & 2 & $9.1 \%$ & \\
\hline Suspicious lesion & 0 & $0.0 \%$ & 0 & $0.0 \%$ & \\
\hline
\end{tabular}

Table 3: Comparison between asymptomatic and symptomatic participants regarding the US, hysteroscopic and histopathological findings.

\begin{tabular}{|c|c|c|c|c|c|c|c|}
\hline & \multicolumn{2}{|l|}{ Histopathology } & \multirow{2}{*}{ 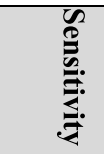 } & \multirow{2}{*}{ 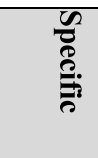 } & \multirow{2}{*}{$\bar{z}$} & \multirow{2}{*}{$\underset{Z}{Z}$} & \multirow{2}{*}{ 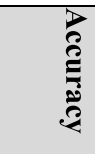 } \\
\hline & $\begin{array}{l}\text { Abnormal } \\
(\mathrm{n}=17)(62.9 \%)\end{array}$ & $\begin{array}{l}\text { Normal } \\
(n=10)(37.1 \%)\end{array}$ & & & & & \\
\hline \multicolumn{8}{|l|}{ US } \\
\hline Endometrial change & & & \multirow[t]{3}{*}{$82.4 \%$} & \multirow[t]{3}{*}{$30.0 \%$} & \multirow[t]{3}{*}{$66.7 \%$} & \multirow[t]{3}{*}{$50.0 \%$} & \multirow[t]{3}{*}{$63.0 \%$} \\
\hline Abnormal $(n=21)$ & $\mathrm{TP}=14(82.3)$ & $\mathrm{FP}=7(70)$ & & & & & \\
\hline Normal $(n=6)$ & $\mathrm{FN}=3(17.7)$ & $\mathrm{TN}=3(30)$ & & & & & \\
\hline \multicolumn{8}{|l|}{ Hysteroscopy } \\
\hline Abnormal $(\mathrm{n}=20)$ & $\mathrm{TP}=16(94.1)$ & $\mathrm{FP}=4(40)$ & \multirow[t]{2}{*}{$94.1 \%$} & \multirow[t]{2}{*}{$60.0 \%$} & \multirow[t]{2}{*}{$80.0 \%$} & \multirow[t]{2}{*}{$85.7 \%$} & \multirow[t]{2}{*}{$81.5 \%$} \\
\hline Normal $(n=7)$ & $\mathrm{FN}=1(5.9)$ & $\mathrm{TN}=6(60)$ & & & & & \\
\hline
\end{tabular}

Table 4: Diagnostic performance of U/S versus hysteroscopy in detection of endomtrial disease 

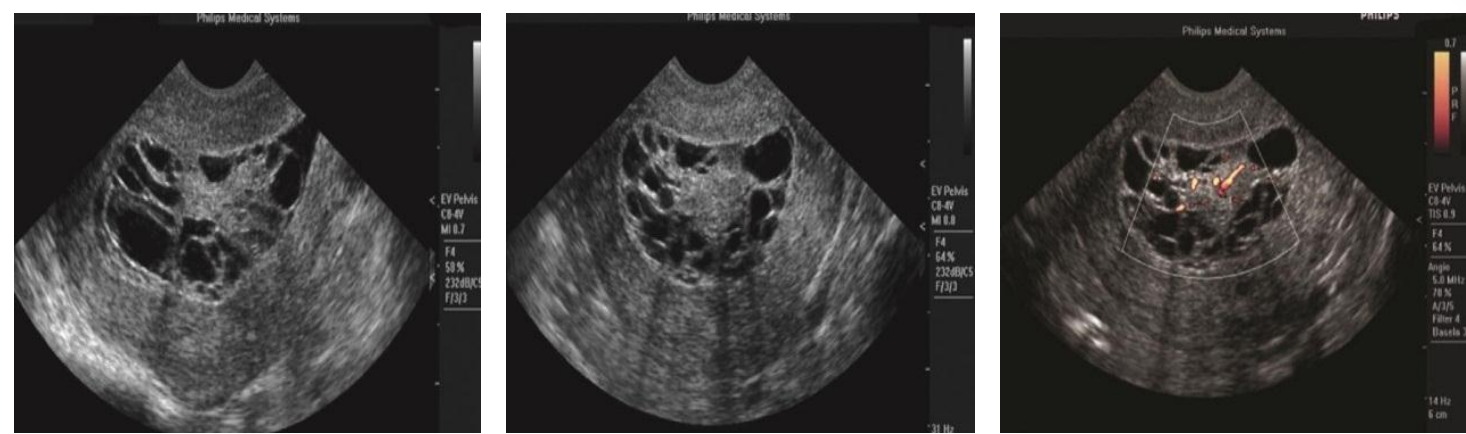

Fig 1: Gray scale transvaginal ultrasound image (A) demonstrating diffuse endometrial thickening with multiple variable sized cystic changes. Gray scale transverse ultrasound image (B) of the same endometrium showing the cystic changes in thickened endometrium. Color Doppler image of the endometrium (C) demonstrating color flow in the central portion of the complex cystic endometrial lesion.Ultrasound diagnosis: endometrial hyperplasia with cystic changes. histopathological diagnosis: complex cystic hyperplasia without atypia: true positive result.
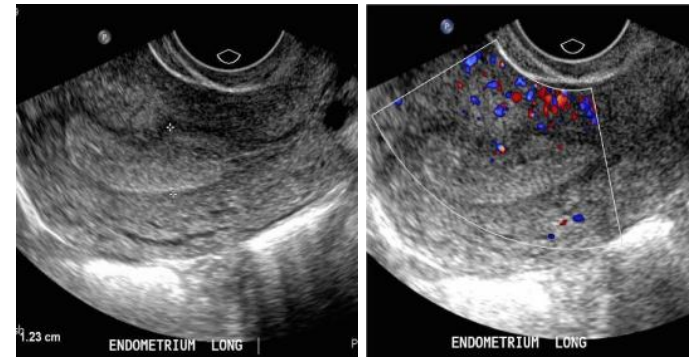

Fig 2: Grayscale (A) and color Doppler (B) sagittal view by transvaginal ultrasound showing a thickened homogenous echogenic endometrium, measuring about $(12.3 \mathrm{~mm})$ in maximal anteroposterior diameter (A), with irregular borders, preserving subendometrial halo. Ultrasound diagnosis, simple endometrial hyperplasia while histopathological result revealed endometrial hyperplasia wirh polyp: true negative result.

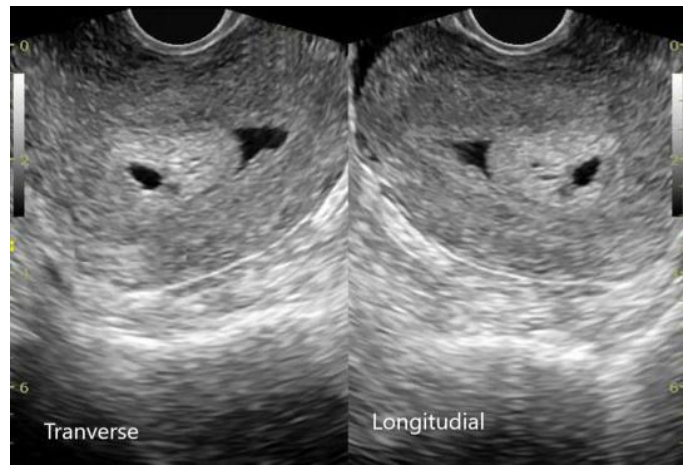

Fig 3: Gray scale transverse (A) and sagittal (B) TVUS images showing well defined echogenic lesion in the endometrial cavity. A thin fluid rim is noted separating the lesion from the endometrial lining at a few places. Cystic changes are noted within this echogenic lesion. Uterine myometrium shows normal echopattern. The sonographic findings suggest endometrial polyp. Ultrasound diagnosis: endometrial polyp which matched with histopathology result, endometrial polyp with no malignant cells.: true positive result.
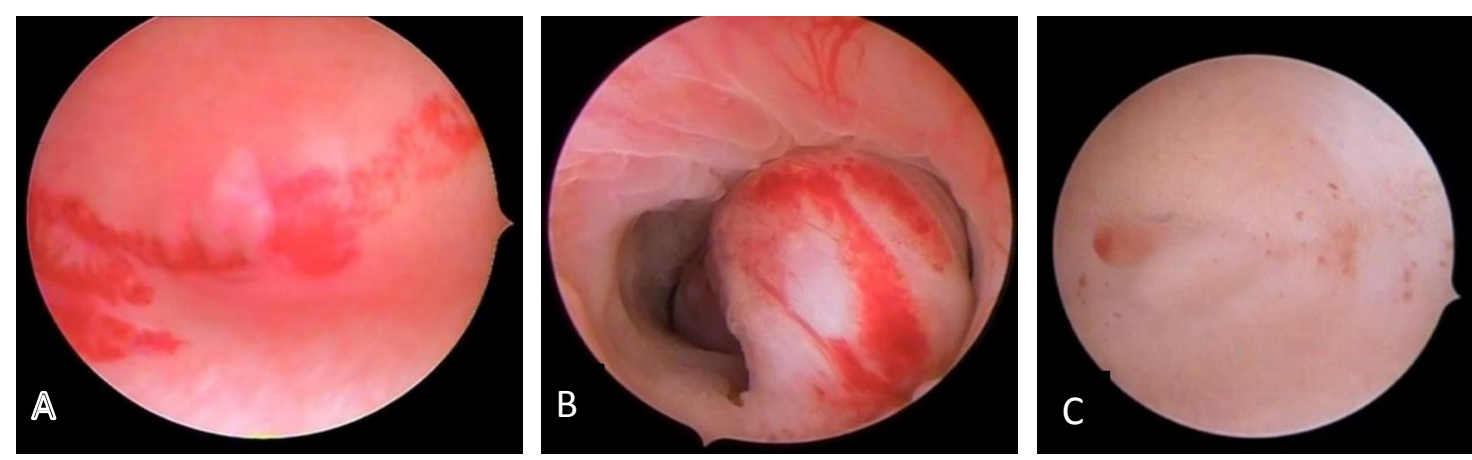

Fig 4: (A) hysteroscopic picture of endometrial hyperplasia which was matched with histopathology: true positive result. (B) hysteroscopic picture of endometrial hyperplasia with polyp which matched with histopathology: true positive result. (C) Thin smooth atrophic endometrium, with petechial and subendometrial hemorrhage which matched with histopathological result: true positive result. 


\begin{tabular}{|l|l|l|l|}
\hline \multirow{2}{*}{ Duration of Treatment } & \multicolumn{2}{|l|}{ Endometrial Change } & \multirow{2}{*}{ P value } \\
\cline { 2 - 3 } & Yes & No & \\
\hline 6 months -2 Years & $7(41.2 \%)$ & $5(50 \%)$ & \multirow{2}{*}{0.965} \\
\hline$>2-4$ Years & $10(58.8 \%)$ & $5(50 \%)$ & \\
\hline Total & $17(100 \%)$ & $10(100 \%)$ & \\
\hline
\end{tabular}

Table 5: Effect of the duration of tamoxifen therapy on endometrial changes in a study group.

\section{DISCUSSION}

This research was included 27 women aged between 32 - 65 years with a mean age of $52.8 \pm 9.3$ years. There were 11 premenopausal, $(40.7 \%)$ and $16(59.3 \%)$ post-menopausal women with two of them being under 40 years, they experienced early menopause,as a result of the drug's influence. The mean duration of TAM therapy was $2.72 \pm 1.34 \mathrm{y}$.

Abnormal vaginal bleeding was experienced by 5 patients (18\%) who were symptomatic VS 22 patients $(82 \%)$ who were asymptomatic with TAM use ranging1-4 years in both groups. The incidence of symptomatic patients in our study was close to that found in Hetta et al. ${ }^{12}$. Also Jindal et al. ${ }^{13}$ conducted study in line with our study, in which 88 $\%$ of the partcipants were asymptomatic and only $12 \%$ were symptomatic.

Endometrial thickening on TVUS is a strong signal that is also suggestive of endometrial pathology 14 . There is no precise definition of an abnormal ET for pre- or postmenopausal women receiving TAM due to its estrogenic effect on subenendometrial gland which leading to increase $\mathrm{ET}^{15}$. Various cutoff values for detection of the endometrial disease in asymptomatic postmenopausal women under TAM were reported, $5,9,10 \mathrm{~mm}{ }^{14,15,16}$, however the findings of the previous studies are hampered by verifying bias and a small sample size. There is consensus about if postmenopausal and premenopausal women experience bleeding and their ET is $>5 \mathrm{~mm},>8 \mathrm{~mm}$ respectively, further investigation is neede $\mathrm{e}^{8,9,10}$

The mean ET in our patients was $9.52 \pm 4.32$ with range $3-30 \mathrm{~mm}$. Six participants $(22.2 \%)$ had average thickness and 21 women $(77.8 \%)$ had endometrial changes, which manifested as, diffuse thickened endometrium without cystic changes in 7 patients(40.7), diffuse thickened endometrium with cystic changes in 11 patients(25.9\%), polyp in one patient (3.7) and atrophic endometrium in 2 patients(7.4). No suspicious endometrial lesion was found. TVUS also revealed 2 patients had adenomyosis as associated lesion and that was expected with TAM. TVUS sometimes detects the polyp as a nonspecific thickening of the central endometrial complex, with or without cystic changes, but it may also skip the diagnosis?.

Our results were matched with Amer et al. ${ }^{1}$ and Le Donne et al. ${ }^{17}$ who reported the same results regarding increased ET in patients receiving TAM after mastactomy. In term of endometrial regularity, we found, 12 patients $(44.5 \%)$ had irregular endometrial line. Although, Irregular or poorly defined ET is usually indicative of malignancy. However, in women receiving TAM, because of underlying benign diseases as adenomyosis, or polyp, poor definition of ET is not a helpful for the diagnosis of endometrial carcinoma. Also our results were in accordance with the results of Le Donne et al. ${ }^{17}$ who found that cystic endometrial appearance was frequent in patients under TAM.

Regarding the hysteroscopic findings, we found that, 7 patients $(25.9 \%)$ had normal endometrium but 20 patienrs $(74.1 \%)$ had abnormal endometrium as follow, I- 15 participants $(55.6 \%)$ had endometrial hyperplasia (EH), (Figure 4). Really inspite of some studies were demonstrated the hysteroscopic morphology for each type of EH as Butureanu et al. (18), but this was not practically established, we only suspected, EH when the endometrium appears thicker on hysteroscopy than standard proliferative endometrium, which has a glistening, mucoid, pinkgray look. It's also likely that it's polypoid in nature.Small cysts and dilated, clogged sinusoids can be visible underneath the surface ${ }^{9}$, but it was difficult to distinguish between its types i,e typical and atypical forms. De Franiscis et al. ${ }^{19}$ reported that uptill now, the EH morphological criteria that detected by hysteroscopy are based on the operator's subjective assessment and, therefore, are not reliable. 2-Three patients $(11.1 \%)$ had polyps, 2 of which were missed by TVUS. It was found that women under TAM, either they experienced vaginal bleeding or not, the endometrial polyps usually are expected but they are common in asymptomatic women ${ }^{9}$. At hysteroscopy, the majority of polyps have smooth, glistening surfaces and are pink-gray to white in colour (Figure. 4). The polyps may be connected to a long or narrow stalk. Unlike endometrial carcinoma, they usually do not bleed readily when touched. Sometimes, the whole polyp or only the tip of the polyp may be hemorrhagic or infarcted ? 3-Our study revealed 2 participants $(7.4 \%)$ had atrophic endometrium. A hysteroscopic diagnosis of atrophic endometrium is established when uterine cavity was regular and the uterine lining was smooth, thin, and pale white with clearly visible network vessels (Figure 4). Regarding the adenomyosis, the hysteroscope plays little role in its detection easpecially the diffused form, so TVUS is superior in detecting of adenomyosis over US.

Regarding the histopathological findings there was 10 patients $(37.1 \%)$. revealed normal reports while 17 patients $(62.9 \%)$ revealed pathology. as follow, 3 patients $(11.1 \%)$ had simple EH, $5(18.5 \%)$ had mixed cystic hyperplasia, 4 (14.8\%)had atypical hyperplsia that noticed in patients used TAM > 2 years, 3 patients $(11.1 \%)$ had polyp. All polyps were detected by hysteroscopy versus only one polyp detected by 
TVUS. Two participants (7.4\%) had endometrial atrophy which was easily detected by both US and hysteroscopy. Our result was in agreement with Amer et al ${ }^{1}$, who found that the most common histopathologic finding was EH. (31.3\%).

In term of atypical EH., Hetta et al. ${ }^{12}$ reported higher incidence with atypia in patients with TAM treatment. However Saccardi et al. ${ }^{20}$ reported less incidence of EH with atypia, This may be attributable to different sample size.

No cases of endometrial cancer was found in our study, several studies were reported a significant correlation between TAM. therapy and benign uterine pathologies and the majority of TAM's proliferative influences on endometrium are unlikely to progress to cancer ${ }^{17,21}$. On other hand some researchers found in their studies cases of endometrial cancer among TAM treated women ${ }^{12}$. But we can attributed that to our small sample size and or short duration of drug treatment, most of our participants didn't take TAM more than 4 years and most of researchers as Le Donne et al. ${ }^{17}$, and Jones et al. ${ }^{22}$ inferred the increase the frequency of endometrial cancer to the long term use of TAM.

Our study revealed that no difference was found between the symptomatic and asymptomatic participants in the incidence of endometrial changes, p>0.05 (Table 3).

Jindal et $\mathrm{al}^{13}$.in agreement with our result, they found that increased endometrial changes On TVUS in asymptomatic postmenopausal women with breast cancer and receiving TAM. But, Cohen et al. ${ }^{16}$ found that the frequency of endometrial pathology was significantly higher in symptomatic patients receiving TAM, which contradicted our findings. In reality, the need for screening and surveillance in asymptomatic TAM patients is a subject of debate among researches, as it has been demonstrated that symptomatic patients are more likely to have a disease that can be easily detected when they visit care facility. If asymptomatic TAM patients were not recommended to keep track of for endometrial assessment, they may be lost.

Upon correlating the ultrasound and hysteroscopic findings and their efficiency in detection of endometrial changes with histopatalogy results, we only checked the correlation and diagnosis from the hand, identification of the presence or absence of endometrial changes, but not the condition of lesion, i,e, benign, orpremalignant (atypical EH.) or malignant. Our study reveled that regarding TVUS, $14(82.3 \%)$ were true positives, 7 patients (70\%) were false positive i.e, inspite of increased the ET in those patients more than the cut off values, but, they revealed normal proliferative endometrium on histopathological reports, 3 patients $(17.7 \%)$ had false negativ sresults, this resulting from missed diagnosis of 2 cases of polyp and one case with normal ET revealed simple EH on histopathology, three cases $(30 \%)$ were true negative (Table 4, Figure 1, 2, 3).
Regarding the hysteroscopic findings when they correlated with histopathology, 16(94.1\%) cases were true positives, $4(40 \%)$ were false positive (i, e, revealed normal with histopatalogy), 1(5.9) was false negative and $6(60 \%)$ were true negatives (Table 4 , Figure 4).

The diagnostic performance of ultrasonography and hysteroscopy in detection of endometrial changes regarding the histopathological reference, we found that hysteroscopy was more sensitive than ultrasound in the diagnosis of endometrial lesions, table 4, and this was consistent with the result of Le Donne et al. ${ }^{17}$ who showed a significant association between hysteroscopy and histological findings regarding the diagnosis of endometrial atrophy, polyps, hyperplasia and cancer $(\mathrm{P}<0.001)$. Similarly, Mukhopadhayay et al. $^{23}$ found a high sensitivity $(71.4 \%)$ and specificity (100.0\%) for hysteroscopy for diagnosing polyps.

Amer et al. ${ }^{1}$ found that TVUS was not accurate in identifying hyperplasia and polyps. Moreover, Dijkhuize et al. ${ }^{24}$ reported that, due to the echogenic, irregular, cystic effect induced by TAM on endometrial stroma and gland and on the myometrium, without essentially inducing epithelial changes, therefore endometrial thickness cannot be used in those patients to define abnormalities ${ }^{25}$. Similarly Jeon et al. ${ }^{5}$ reported that TAM causes subendometrial glandular hypertrophy, so ET can increase even in absence of pathologies ${ }^{15}$. So some researchers suggested that TVUS endometrial testing has limited predictive value in asymptomatic patients with false positive result. Additionally, TVUS has been confirmed to provide false-negative diagnoses of small polyps, localised atypical hyperplasia and endometrial cancer ${ }^{7}$.

On Contrary, Hetta et al. ${ }^{12}$ and Cohen et al. ${ }^{16}$ disagree with our result, they revealed that TVUS was more diagnostic than hysteroscopy.

In the paractice, inspite the value of hysteroscopy in detecting the endometrial pathology, however it doesn't distinguish between typical and atypical hyperplasia, unless the latter is associated with focal lesion, additionally, in this situation hysteroscopy is only suspecting but not confirming the pathology. Similarly Barati et al. ${ }^{26}$ reported that, EH can develop visible space-occupying lesions that are simple to diagnose by hysteroscopy, but it may not noticeable, particularly in the early stages of the disease, so, histopathology tests are essential for the definitive diagnosis of exact pathology.

We couldn't find a correlation between the duration of TAM therapy and the occurrence of endometrial changes, similarly Donnez et al. ${ }^{27}$ didn't observed any relation between duration of TAM use and endometrial changes, nevertheless the previous authors found that increased the incidence of endometrial cancer in patients used TAM for more than four years. In the present study we also found, inspite there no relation was found between the incidence of endometrial changes and duration of TAM therapy ,but, there was association between the

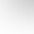


latter and the severity of endometrial changes i, e, our study revealed all patients who had atypical hyperplasia were used TAM > 2years duration. This means that incidence of premalignant lesion is increased with lengthing the duration of treatment.

Despite the fact that our research found a higher rate of endometrial changes in asymptomatic patients than previous studies, we assume that this is a strength point of this study, because it prompts gynecologists to carefully screen asymptomatic women receiving TAM. The study's limitations include the small sample size and absence of patient that used TAM for more than 4 years.

\section{CONCLUSION}

TVUS is a suitable for endometrial screening for intrauterine pathology. However, because of certain discrepancies between TVUS and histopathological results in TAM treated women, TVUS is not the ideal tool for evaluating the endometrium in those patients. The utility of the hysteroscopic image processing helps in the triage of women who require endometrial surveillance, so it will reduce the pathologist's needless workload and the patient's apprehension while waiting histopathology result. Nevertheless hysteroscope cannot establish a conclusive diagnosis of premalignant or malignant lesion, but it provides a direct view of the endometriaum for detection of focal lesion and chance of conducting targeted biopsies to create a definitive diagnosis.

\section{REFERENCES}

1. Amer AA, Nawar EN, Elnemr AA, et al. Effects of Tamoxifen and Aromatase Inhibitors on Endometrium in Breast Cancer Patients at Zagazig University Hospitals. ZUMJ 2019; 25 (2); 269-77.

2. Lee S, KimYH, Kim SC et al. The effect of tamoxifen therapy on the endometrium and ovarian cyst formation in patients with breast cancer. Obstet Gynecol Sci. 2018; 61(5): 615-20.

3. Krauss K and Stickeler E. Endocrine Therapy in Early Breast Cancer. Breast Care. 2020;15:33746.

4. Emons G, Mustea A and Tempfer C. Tamoxifen and Endometrial Cancer: A Janus-Headed Drug. Cancers (Basel). 2020; 12(9):2535.

5. Jeon J, Kim SE, Lee DY, et al. Factors associated with endometrial pathology during tamoxifen therapy in women with breast cancer: a retrospective analysis of 821 biopsies. Breast Cancer Res Treat. 2020; 179(1):125-130.

6. Lee M, Piao J and Jeon MJ. Risk Factors Associated with Endometrial Pathology in Premenopausal Breast Cancer Patients Treated with Tamoxifen. Yonsei Med J. 2020;61(4):31722.

7. Pop-Trajković-Dinić S, Ljubić A, Kopitović V, et al. The role of hysteroscopy in diagnosis and treatment of postmenopausal bleeding. Vojnosanitetski pregled. 2013;70(8):747-50

8. Park YR, Lee SW, Kim Y, et al. Endometrial thickness cut-off value by transvaginal ultrasonography for screening of endometrial pathology in premenopausal and postmenopausal women. Obstetrics \& Gynecology Science. 2019; 62(6):445.

9. Fong K, Causer P, Atri M, et al. Transvaginal US and Hysterosonography in Postmenopausal Women with Breast Cancer Receiving Tamoxifen: Correlation with Hysteroscopy and Pathologic Study. RadioGraphics. 2003; 23:13755

10. Smith- Bindman R, Weiss E and Feldstein V. How thick is too thick? When endometrial thickness should prompt biopsy in postmenopausal women without vaginal bleeding. Ultrasound in Obstetrics and Gynecology: The Official Journal of the International Society of Ultrasound in Obstetrics and Gynecology. 2004; 24(5):558-65.

11. ACOG committee Opinion summary, Number 800. The use of hysteroscopy for the diagnosis and treatment of intrauterine pathology. Obstetrics \& Gnecology. 2020; 135(3): 754-6.

12. Hetta WM, Samy A, Romeih M, et al. Egyptian Journal of Radiology and Nuclear Medicine 2019; 50:18.

13. Jindal A, Mohi MK, Kaur M, et al. Endometrial evaluation by ultrasonography, hysteroscopy and histopathology in cases of breast carcinoma on Tamoxifen therapy. J Mid-life Health. 2015;6:5965.

14. Love CD, Muir BB, Scrimgeour JB, et al. Investigation of endometrial abnormalities in asymptomatic women treated with tamoxifen and an evaluation of the role of endometrial screening. J Clin Oncol. 1999;17: 2050-4.

15. Franchi M, Ghezzi F, Donadello N, et al. Endometrial thickness in tamoxifen-treated patients: an independent predictor of endometrial disease. Obstetrics \& Gynecology. 1999; 93(6):1004-8.

16. Cohen I, Azaria R, Shapira J, et al. Significance of secondary ultrasonographic endometrial thickening in postmenopausal tamoxifen-treated women. Cancer. 2012; 94:256-66.

17. Le Donne M, Alibrandi A, Ciancimino L, et al. Endometrial pathology in breast cancer patients: Effect of different treatments on ultrasonographic, hysteroscopic and histological fndings. Oncology Letters. 2013; 5: 1305-10.

18. Butureanu SA, Socolov RM, Pricop F, et al. Diagnostic hysteroscopy in endometrial hyperplasia. Gynecologic and Obstetric Investigation. 2005;59(2):59-61.

19. De Franciscis P, Riemma G, Schiattarella A, et al. Concordance between the hysteroscopic diagnosis of endometrial hyperplasia and histopathological examination. Diagnostics. 2019; 9(4):142.

20. Saccardi C, Gizzo S, parrelli TS, et al. Endometrial surveillance in tamoxifen users: role, timing and accuracy of hysteroscopic investigation: observational longitudinal cohort study. Endocr Relat Cancer. 2013; 20(4): 455-62.

21. Jordan VC and Assikis VJ. Endometrial carcinoma and tamoxifen: clearing up a controversy. Clinical Cancer Research. 1995; $1(5): 467-72$ 
22. Jones ME, van Leeuwen FE, Hoogendoorn WE, et al. Endometrial cancer survival after breast cancer in relation to tamoxifen treatment: pooled results from three countries. Breast Cancer Res. 2012; 14(3): 91.

23. Mukhopadhayay S, Bhattacharyya SK, Ganguly $\mathrm{RP}$, et al. Comparative evaluation of perimenopausal abnormal uterine bleeding by transvaginal sonography, hysteroscopy and endometrial biopsy. Journal of the Indian Medical Association. 2007; 105(11):624-6.

24. Dijkhuize FP, Brölmann HA, Oddens BJ, et al. Transvaginal ultrasonography and endometrial changes in postmenopausal breast cancer patients receiving tamoxifen. Maturitas. 1996; 25(1):4550.

25. Neven P, Vergote I. Should tamoxifen users be screened for endometrial lesions?. The Lancet. 1998; 351(9097):155-7.

26. Barati M, Masihi S, Moramezi F. Hysteroscopic view of endometrial hyperplasia. Pakistan Journal of Medical Sciences. 2008, 1;24(1):65.

27. Donnez O and Dolmans M-M. The current place of medical therapy in uterine fibroid management. Best Practice \& Research Clinical Obstetrics \& Gynaecology. 2018; 46: 57-65. 